\title{
Block Scheduling Strategies and Perceptions
}

\author{
Ryan Kilpatrick \\ Gwynedd-Mercy University
}

Received: August 6, 2014 Accepted: Sep. 27, 2014 Published: November 1, 2014

doi:10.5296/jse.v4i4.6327

URL: http://dx.doi.org/10.5296/jse.v4i4.6327

\begin{abstract}
This action research examines block scheduling at the high school level. Participants from a suburban high school in Pennsylvania answered questions about successful and unsuccessful strategies and their perceptions of block scheduling. Many high schools across the country have implemented a block schedule format, but questions remain about its benefits and drawbacks. The results received from fourteen teacher participants and two administrators point to an overall positive attitude toward block scheduling. In their responses, participants identify benefits, drawbacks, successful and unsuccessful strategies used in a block schedule.
\end{abstract}

Keywords: Block, Schedule, Strategy, Perceptions, Participants 


\section{Introduction}

This action research project identifies what strategies have worked best for teachers teaching in a block schedule format and their opinions of block scheduling. Block scheduling is a format in schools where periods are around ninety minutes long instead of the traditional forty-five minutes. Classes meet every day for one full semester, instead of forty-five minutes every day for the entire year. As you might suspect, this drastically changes the teacher's approach to planning and delivery of material. The research goal is to identify successful strategies teachers can use in a block format and teacher/administrator perceptions of block scheduling.

This area of focus involves teaching, specifically what strategies and methods teachers use in a block schedule format. The strategies and methods that other teachers have used in the past are not within the researcher's control, the research will aim to identify successful and unsuccessful strategies. Having this information available to other beginner teachers will be valuable as a resource for what teaching methods to use in a block schedule. This is an area that can be improved if teachers are willing to share their successful methodology with peers.

Teachers all over the world use different strategies to reach students. Block scheduling provides a unique challenge to educators because it requires teaching students for ninety minutes each day and being able to utilize that time efficiently. There are certain teachers who struggle with this format and others who may fear it. By actively researching and analyzing the successful and failed methods, this research will be a guide or reference for other teachers working within a block schedule.

\section{Methodology}

\section{Research Design}

This action research project was carried out using a survey sent via email to teachers and an interview with two high school administrators. The survey consisted of thirteen questions (see Appendix A) in which participants discussed block scheduling strategies and its affect on their classroom. The interview portion was conducted in person, consisted of seven questions (see Appendix B) and was recorded for further analysis. The surveys provide qualitative information in the form of written data and the interviews also provide qualitative information in the form of narrative data. Any information received can also be interpreted using quantitative methods. The survey and interview questions were created by the researcher to identify teacher and administrator strategies and perceptions of block scheduling.

\section{Participants}

This action research project utilizes a purposive sample. The teachers surveyed and administrators interviewed are the gatekeepers of this action research project. This population was selected because of convenience and the researcher's knowledge of the population. A questionnaire was provided to teachers working at a suburban high school in the Northeast 
region of the United States, which uses a block schedule. There are approximately 120 teachers working at the school and the demographics are unknown. Two administrators at the same high school were interviewed to gain insight on their experience with block scheduling. All of the participants have experience teaching in a block schedule format. The participants were contacted via email after permission was granted by the high school's administration. The only exclusion criteria in effect was if a teacher in the population has no experience teaching in a block schedule format, i.e., it is their first year working in a block schedule.

\section{Data Collection}

Data was collected from teachers using a survey and from administrators during an interview. Interviews were recorded for further analysis at a later time. The survey and interview questions contain multiple choice and open-ended questions, with the majority being open ended. The questions have been constructed in an open ended manner so the participants could express any feelings they have on the topic of block scheduling. Questions with specific answers, like multiple choice, are not as valuable in determining strategies used in block scheduling. In order to analyze and identify successful and unsuccessful strategies, questions need to be open-ended so participants can explain strategies in detail and reasons for success or failure.

\section{Procedures}

The first step in the action research project was defining the topic of research. After selecting to research successful and unsuccessful strategies used in block scheduling, data collection techniques were examined. Survey and interview questions were determined to be the most effective strategy for gathering this type of information. The survey and interview questions have an open ended design to allow the participants to express their views and experience with block scheduling. Administration at the high school selected was contacted to request permission to send the survey by email to teachers working in the school. When permission was granted the informed consent form and survey were distributed to participants. Next, two administrators were interviewed for their perspectives on block scheduling. After the surveys and interviews were complete, the researcher collected all data for analysis and interpretation.

\section{Limitations}

One potential threat was that administration may not grant permission to distribute the survey to the teachers at the high school selected. If permission was denied, another school using block scheduling would have been selected. The validity of the research will be hard to contradict because the strategies used by this particular population of teachers are subjective. The participants identified through the survey what they think are successful and failed strategies, which might be different according to other teachers. The participants surveyed have a wide range of experience. If information had been received only from teachers with very limited experience (1-2 years), the validity of the research should still remain strong because teachers with all experience can implement successful strategies. 
Analysis

Feedback was analyzed to determine what teaching methods have been successful in the classroom and which did not work so well and why. Survey and interview questions were analyzed by comparing the answers received. Categorizing the answers by their similarities highlights which strategies tend to work more than others. Analysis highlights characteristics of successful and unsuccessful teaching methods. The surveys received from teachers provide qualitative information in the form of written data and the interviews also provide qualitative information in the form of narrative data. Data received allowed for calculating percentages based on certain characteristics in the answers, which were considered quantitative data. The quantitative data found in the research was calculated by the researcher. After identifying patterns and relationships between the answers, data was interpreted by the researcher.

\section{Results}

Participant experience ranged from three to nineteen years working in a block schedule. Although this is a large experience range, there were not clear differences between experience levels. Only $14 \%$ of participants would prefer to teach in a traditional schedule, citing the fact that a traditional schedule allows them to teach the same students all year and it is easier to hold the student's attention. A majority of the teachers would prefer to teach in a block schedule. They acknowledge that a block schedule allows more time for processing and lab work; requires less paperwork and fewer students to manage; and the additional time allows for a variety of teaching methods and more in depth content. According to Zepeda and Mayers (2006), teachers report feeling less stress when working with a block schedule because it results in fewer class preparations.

When asked which schedule is better for students, $36 \%$ of teachers chose the traditional schedule. This shows that while more teachers prefer to teach in a block schedule, less think it is better for students. The participants state that having core subjects all year would be more beneficial to students because they have more time overall to practice and master skills. Advocates for block scheduling cite that more can be accomplished in an efficient manner because there is less time transitioning between classes. Teachers reported that students in a block schedule take less time adjusting to different classes, which allows them to focus more on the content (Fisher \& Frey, 2007). Block scheduling is also more similar to a college schedule because classes are longer and students only have four or five to worry about, compared to seven or eight in a traditional schedule. Administrators also agree that block scheduling is better for students because it prepares them for college and creates more flexibility within their schedules. Students can also take more classes in year, such as two languages or two math courses.

None of the participants believe block scheduling has any impact on keeping students' attention. The participating teachers all state they have no trouble keeping students engaged because they plan several different activities for one period. When teachers sense students are becoming disengaged, they transition to a new activity. Block scheduling effect on teacher-student relationships received mixed responses. Some teachers acknowledge they had 
stronger relationships with students they taught for a full year, while others think the additional time given in a block schedule is beneficial to building relationships. One participant states that block scheduling helps build the relationship with students because it allows for more time on a day to day basis for interaction. Teachers have fewer students in a block schedule, which allows for stronger relationships.

Participants acknowledge that block scheduling is better for any constructivist activity, especially activities that involve cooperative learning, the use of technology, or activities with multiple steps. Block scheduling is beneficial for teachers that use different activities and methods within one block. In an article by Flynn, Lawrenz, and Schultz (2005), the research data shows no differences in a teachers' use of whole-class and small-group instruction between traditional and block scheduling. When asked what strategies have been used successfully in the block schedule, participants responded with a wide range of methods such as lecture, group work, independent work, stations for skill work, lab time, discussion, technology integration, and presentations. Although all of these methods are used in a traditional schedule, this research shows that teachers can incorporate more of these strategies within one block. According to Biesinger, Crippen, and Muis (2008), research indicates that most teachers used traditional instructional activities in their everyday lesson plans. Traditional instructional activities include lecture, note taking, individual practice, and review of homework problems. However, almost all instructors used at least three different instructional activities during the block period and some used four different activities (Biesinger, et al., 2008). A majority of the teachers state that preparation is the key to running an efficient class for a block schedule and keeping student's attention. All of the participants state that lecturing too much will be an unsuccessful strategy. When teachers lecture too long, students lose interest and focus.

All participants stated that no professional development specifically tailored to teaching in a block schedule is available. This finding is consistent with research done in the past. Teachers may not be using class time any differently or properly taking advantage of the extra time given for a block period. Flynn et al. (2005) suggests that this is because teachers do not have the proper training and are not receiving enough ongoing professional development to develop these skills. Professional development is geared toward integrating technology, differentiating instruction, and using different strategies and techniques in the classroom, which can all be helpful in a block schedule. Instead, guidance on handling the block schedule is given by teacher leaders when assistance is needed. Although participating teachers do not clarify if this type of professional development would be beneficial, administration acknowledges that teachers who are not used to teaching in a block schedule will create lessons not conducive to the time frame. The administrators also state that teachers need to use different activities, transition smoothly, and plan to use the time given efficiently.

All of the participating teachers follow a similar plan in their classroom. A typical day consists of a warm-up activity, a short instructional presentation which incorporates class discussion and demonstrations, an activity incorporating the content, and a brief review wrap-up. Some teachers also use class time to review homework and give students time at the 
end of the class to start homework. Vaughn (2012) suggests teachers should focus the entire class period around one concept and try to teach that concept using a variety of different methods, which will help with students' short attention spans. The main theme from teachers and administrators is stressing the importance of good planning and preparation to utilize the block schedule efficiently and effectively.

\section{Conclusion}

Overall, perceptions of block scheduling are positive. The majority of participating teachers prefer to teach in a block schedule and think it is the best schedule for students. Administrators reiterated the same feelings and even stated that most teachers would be upset if the school transitioned to a traditional schedule. Participants stress that proper planning is vital for running an efficient and engaging class in a block schedule. Utilizing different strategies and activities to teach material is important for keeping students engaged and all teachers warn against lecturing too much. Participants did not clarify if professional development specifically tailored to block scheduling would be beneficial; however, the results given above by teachers and administrators can serve as a guide to any teacher working in a block schedule.

\section{References}

Biesinger, K. D., Crippen, K. J., \& Muis, K. R. (2008). The Impact of Block Scheduling on Student Motivation and Classroom Practice in Mathematics. NASSP Bulletin, 92(3), 191-208. http://dx.doi.org/10.1177/0192636508323925

Fisher, D., \& Frey, N. (2007). A tale of two middle schools: The differences in structure and instruction. Journal of Adolescent \& Adult Literacy, 51(3), 204-211. http://dx.doi.org/10.1598/JAAL.51.3.1

Flynn, L., Lawrenz, F., \& Schultz, M. J. (2005). Block Scheduling and Mathematics: Enhancing Standards-Based Instruction?. NASSP Bulletin, 8914-23. http://dx.doi.org/10.1177/019263650508964203

Vaughn, B. (2012, January 14). The Effects of Block Scheduling: Strategies for Time Management. AP Central. Retrieved July 3, 2014, from http://apcentral.collegeboard.com/apc/members/courses/teachers_corner/49336.html

Zepeda, S. J., \& Mayers, R. (2006). An Analysis of Research on Block Scheduling. Review Of Educational Research, 76(1), 137-170. http://dx.doi.org/10.3102/00346543076001137

\section{Appendix A}

Teacher Survey

Teachers received the following survey with about block scheduling.

1. How many years experience do you have teaching in a block schedule?

2. Which type of schedule would you prefer to teach in, block or traditional? Why? 
3. Which type of schedule do you think is better for students? Why?

4. What impact does the block schedule have on your ability to keep student's attention?

5. How does the block schedule affect your relationship with students?

6. What percentage of the class period is used for lecture based instruction?

7. Is there enough time in your class to review the previous day's lesson?

8. Is there enough time for students to comprehend the information taught during the period?

9. Is block scheduling better for certain teaching strategies? If so, which strategies?

10. What strategies have you used successfully in the block schedule? Why did they work?

11. What strategies have you used unsuccessfully in the block schedule? Why didn't they work?

12. Is professional development available that is specifically tailored to teaching in a block schedule?

13. Please provide a brief summary of a typical day in your classroom.

\section{Appendix B}

Administrative Interview

Administrators will be interviewed face to face and it will be recorded. The questions for the interview are listed below.

1. Does professional development for teachers at this school differ from professional development from teachers working in a traditional schedule?

2. Do teachers take advantage of the block schedule format based on your observations?

3. What successful strategies have you noticed in the classroom?

4. What unsuccessful strategies have you noticed in the classroom?

5. What impact does the block schedule have on the teacher's ability to keep student's attention?

6. How does the block schedule affect teacher student relationships?

7. Which type of schedule is better for students? Why? 
Appendix C

\section{Informed Consent Form}

GWYNEDD MERCY UNIVERSITY

Informational Letter/Informed Consent Form

Adult Participants

Title of Study: Block Scheduling Strategies and Perceptions

Principle Investigator:

Email address:

Faculty Advisor:

Study Contact telephone number:

Study Contact Email:

\section{$\underline{\text { Introduction }}$}

You are being asked to take part in a research study. To join the study is voluntary. You may refuse to join, or you may withdraw your consent to be in the study, for any reason, at any time, without penalty.

Research studies are designed to obtain new knowledge. This new information may help people in the future. You may not receive any direct benefit from being in the research study. There also may be risks to being in research studies.

Details about this study are discussed below. It is important that you understand this information so that you can make an informed choice about being in this research study.

You will be given a copy of this consent form. You should ask the researchers named above, or staff members who may assist them, any questions you have about this study at any time.

\section{Purpose of the Study}

The purpose of this research study is to learn about successful strategies and failed strategies used by educators teaching in a block schedule.

You are being asked to be in the study because you currently teach in a block schedule format or are an administrator at a school that uses block scheduling. 


\section{1) Macrothink}

\section{Description of the Study}

Teachers will be asked to complete a survey with multiple choice and open ended questions about block scheduling. Administrators will be interviewed about their views on block scheduling by the principle researcher.

The amount of time required to participate in the study is approximately 30 minutes to complete the survey (teachers) and 30 minutes to complete the interview (administrators). There will not be any follow up to this survey or interview.

\section{$\underline{\text { Risks and Discomforts }}$}

There may be uncommon or previously unknown risks. You should report any problems to the researcher. There are no known risks.

\section{Benefits}

There may be no direct benefits of participating in this study. However, the knowledge received may be of value to other teachers working in a block schedule or schools interested in implementing a block schedule.

\section{Protection of Privacy}

Participants will not in any report or publication about this study. Although every effort will be made to keep research records private, there may be times when federal or state law requires the disclosure of such records, including personal information. This is very unlikely, but if disclosure is ever required, Gwynedd Mercy University will take steps allowable by law to protect the privacy of personal information. In some cases, your information in this research study could be reviewed by representatives of the University for purposes such as quality control or safety. If any presentations or publication result from this research, I will not be identified by name.

The survey will be anonymous and does not require any personal information. For the interview portion with administrators, information will be reported anonymously.

\section{Compensation}

You will not receive anything for taking part in this study.

Additionally, there will be no costs for being in the study.

\section{Questions}

You have the right to ask, and have answered, any questions you may have about this research. If you have questions, or concerns, you should contact the researchers listed on the first page of this form.

All research on human volunteers is reviewed by a committee that works to protect your rights and welfare. If you have questions or concerns about your rights as a research participant you may contact, anonymously if you wish, the Institutional Review Board at 215-646-7300. 


\section{Voluntary Consent to Participate}

Participation in this study is entirely voluntary. Refusal to participate will involve no penalty or loss of benefits to you. You are free to withdraw, or to discontinue your participation in this study at any time prior to submission of the survey without penalty or consequence.

If you agree to participate in this research study, please select yes on the electronic survey Informed Consent page.

\section{Appendix D}

\section{Informed Consent Signature Page}

Title of Study: Block Scheduling Strategies and Perceptions

\section{Principle Investigator:}

\section{Participant's Agreement:}

I have read the information provided above. I have asked all the questions I have at this time. I voluntarily agree to participate in this research study.

Signature of Research ParticipantDate

Printed Name of Research Participant

Signature of Person Obtaining ConsentDate

Printed Name of Person Obtaining Consent 